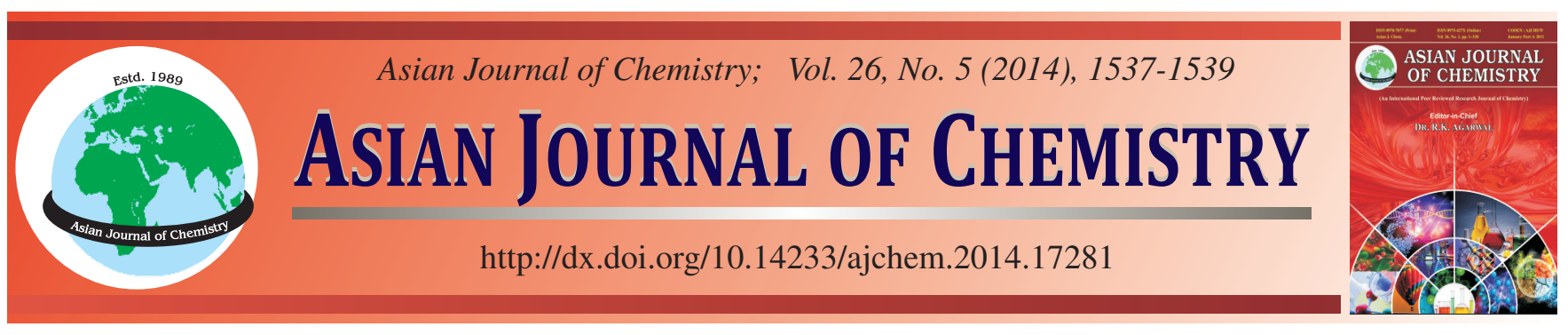

\title{
Hydration Process, Composition and Microstructure of Slag-Cement Paste Blends Containing 0-70 \% Slag at Different Curing Temperatures $\dagger$
}

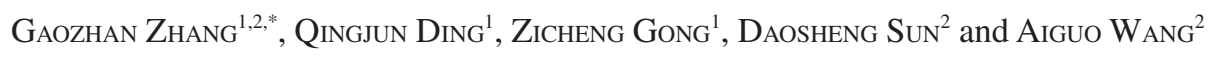

${ }^{1}$ School of Materials Science and Engineering, Wuhan University of Technology, Wuhan 430070, P.R. China

${ }^{2}$ School of Materials and Chemical Engineering, Anhui Jianzhu University, Hefei 230601, P.R. China

*Corresponding author: E-mail: 38830811@qq.com; gaozhanzhang@126.com

Published online: 1 March 2014;

\begin{abstract}
The hydration process, composition and microstructure of slag-cement paste blends with $0-70 \%$ slag at different curing temperatures have been studied by hydration heat test, XRD, high resolution solid-state ${ }^{29}$ Si MAS NMR and SEM. The results demonstrate that curing temperatures and dosage of slag are the key factors to influence hydration process, microstructure of slag-cement pastes during setting. With the curing temperatures increase, the exothermic peak shift forwards, the amount of calcium hydroxide $(\mathrm{CH})$ decreased, the maximum hydration heat power, the microstructure parameters of calcium silicate hydrate $(\mathrm{C}-\mathrm{S}-\mathrm{H}): \mathrm{Q}^{2} / \mathrm{Q}^{1}$ ratios, $\mathrm{Al} / \mathrm{Si}$ ratios, the mean aluminosilicate chain length (MCL) for C-S-H, the hydration rate of cement $\left(\alpha_{c}\right)$, the hydration rate of slag $\left(\alpha_{s}\right)$ and the degree of polymerization of C-S-H increase and the morphology of C-S-H gradually tends to be more bulky and dense. Similarly, with the dosage of slag in the blends increase, the exothermic peak shift afterwards, the maximum hydration heat power and the amount of calcium hydroxide decrease, the microstructure parameters of C-S-H: $\mathrm{Q}^{2} / \mathrm{Q}^{1}$ ratios, $\mathrm{Al} / \mathrm{Si}$ ratios and $\mathrm{MCL}, \alpha_{\mathrm{c}}$, the degree of polymerization of C-S-H increase and the morphology of C-S-H gradually changes from needle and flocculate to graininess.
\end{abstract}

Keywords: Curing temperatures, Slag, Microstructure, ${ }^{29}$ Si MAS NMR.

\section{INTRODUCTION}

Granulated blast-furnace slag is one of the admixtures used most widely in concrete for its potential pozzolanic activity. The effect of hydration reaction on the microstructure of slag-cement blend paste is one of the most important factors, especially the secondary hydration reaction from slag. The clinker of Portland cement is hydrated first in slag-cement blend paste and then the slag is activated by the first hydrated resultant alkali of calcium hydroxide and sulfate gypsum and the secondary hydration reaction take place ${ }^{1}$. Temperature is a key factor which affected the hydration kinetics and the microstructure of hydration products $^{2}$. The influence of temperature on the microstructure of different gel system was reported by previous workers ${ }^{3-6}$. In this paper, we have used the hydration heat test, XRD, solidstate ${ }^{29} \mathrm{Si}$ MAS NMR and SEM to characterize the hydration process, composition and microstructure of hydrated slag-cement pastes at different curing temperatures.

\section{EXPERIMENTAL}

Used a P, I 52.5 cement was produced by Huaxin cement Co., LTD with the bulk metal oxide compositions given in
Table-1 and with a specific surface of $346 \mathrm{~m}^{2} / \mathrm{kg}$. A ground blast furnace slag from Jiangnan grinding Co., Ltd. was used. The chemical composition of slag is shown in Table- 1 with a specific surface of $374 \mathrm{~m}^{2} / \mathrm{kg}$.

Sample preparation and characterization method: The slag-cement pastes were prepared by mixing the replacement per cent slag for cement was 0 to $70 \%$ by weight and all hydration mixtures employed a water binder ratio of 0.35 .

Hydration heat development of slag-cement pastes were measured using a TAM Air Thermal activity trace microcalorimeter at 20,35 and $50{ }^{\circ} \mathrm{C}$. XRD of powdered samples were recorded on a Bruker D8 ADVANCE X-ray diffractometer with $\mathrm{CuK}_{\alpha}$ radiation at $40 \mathrm{KV}$ and $40 \mathrm{~mA}$. The specimens were collected in the $2 \theta$ range $5.0-75.0^{\circ}$ with a scanning rate of $2 \%$ $\mathrm{min}$. The microscope used was a JSM $4800 \mathrm{f}$ SEM operated in secondary electron detection mode with high-vacuum and an acceleration voltage of $20 \mathrm{kV}$. Solid-state ${ }^{29} \mathrm{Si}$ NMR spectra were obtained with a Bruker AVANCE III 400MHz NMR spectroscope working at $79.3 \mathrm{MHz}$. Spectra were recorded with MAS techniques, with sample spinning rates of $8 \mathrm{kHz}$, with a pulse width $4.0 \mu \mathrm{s}$, with a pulse recycle delay of $5.0 \mathrm{~s}$.

†Presented at The 7th International Conference on Multi-functional Materials and Applications, held on 22-24 November 2013, Anhui University of Science \& Technology, Huainan, Anhui Province, P.R. China 
TABLE-1

BULK OXIDE COMPOSITION FOR THE P. I 52.5 CEMENT AND SLAG, wt \%

\begin{tabular}{cccccccccc}
\hline Oxide & $\mathrm{SiO}_{2}$ & $\mathrm{Al}_{2} \mathrm{O}_{3}$ & $\mathrm{Fe}_{2} \mathrm{O}_{3}$ & $\mathrm{CaO}$ & $\mathrm{MgO}$ & $\mathrm{SO}_{3}$ & $\mathrm{Na}_{2} \mathrm{O}$ & $\mathrm{K}_{2} \mathrm{O}$ & Loss \\
\hline Cement & 21.35 & 4.67 & 3.31 & 62.60 & 3.08 & 2.25 & 0.21 & 0.54 & 0.95 \\
Slag & 28.15 & 16.00 & 1.10 & 34.54 & 6.00 & 0.32 & 0.46 & 0.45 & 2.88 \\
\hline
\end{tabular}
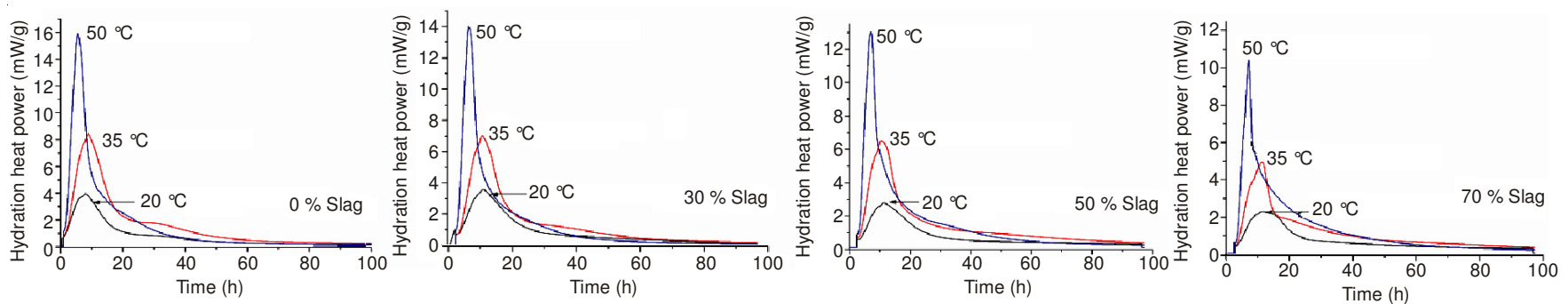

Fig. 1. Hydration heat power of slag-cement pastes

\section{RESULTS AND DISCUSSION}

Hydration heat analysis: Fig. 1 shows that the hydration heat power significantly increased and the position of exothermic peak shift afterwards with the increasing reaction temperature from 20 to $50{ }^{\circ} \mathrm{C}$ during the time period of 0 to $40 \mathrm{~h}$. At the same time, the hydration heat power decreased with the increasing dosage of slag from 0 to $70 \%$. The maximum hydration heat power of net cement paste at 20,35 and $50{ }^{\circ} \mathrm{C}$ were up to $3.9,8$ and $16 \mathrm{~mW} / \mathrm{g}$, respectively. However, the maximum hydration heat power of slag-cement with $70 \%$ slag at 20,35 and $50{ }^{\circ} \mathrm{C}$ was only up to 2,5 and $10.5 \mathrm{~mW} / \mathrm{g}$. These results suggested that the hydration of blends pastes were promoted as increasing reaction temperatures, the maximum hydration heat power gradually decreased as increasing slag.

X-Ray diffraction analysis: XRD patterns for the 28day-old slag-cement pastes blends containing 30-70 \% slag at 20, 50 and $80^{\circ} \mathrm{C}$ are shown in Fig. 2, which indicate that the crystalline phases present in the slag-cement pastes including calcium hydroxide, AFt, $\mathrm{C}_{3} \mathrm{~S}, \mathrm{C}_{2} \mathrm{~S}$ and possibly some $\mathrm{AFm}$ that contains carbonate ions. Smaller amounts of calcium hydroxide, $\mathrm{C}_{3} \mathrm{~S}$ and $\mathrm{C}_{2} \mathrm{~S}$ appeared progressively in the blended pastes as the curing temperatures increased, which demonstrate

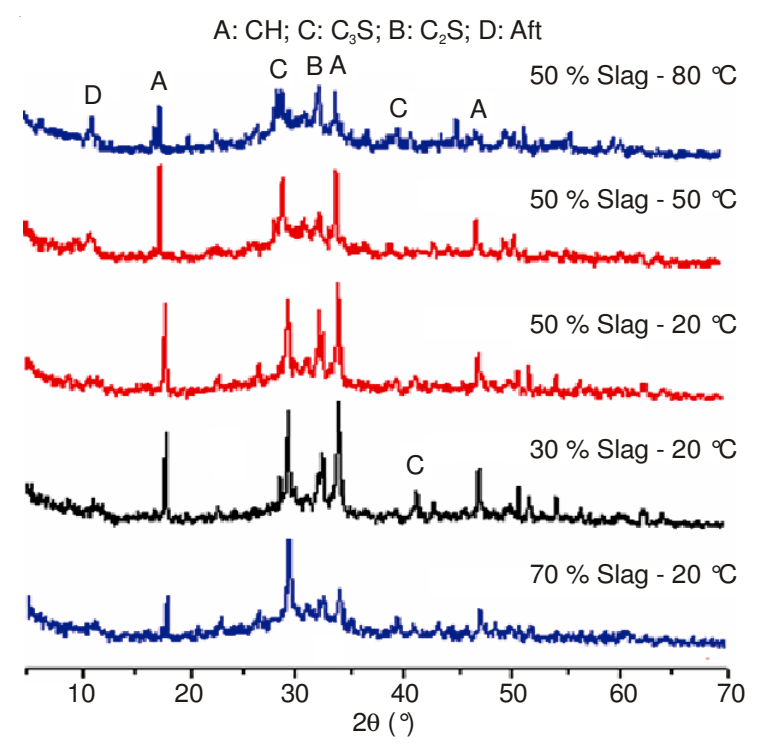

Fig. 2. XRD patterns of slag-cement pastes that the hydration of cement and the pozzolanic activity of slag can be promoted obviously with the curing temperatures increased. XRD data demonstrate that the peaks of $\mathrm{C}_{3} \mathrm{~S}, \mathrm{C}_{2} \mathrm{~S}$ and calcium hydroxide decreased with slag increased due to the pozzolanic reaction of slag with calcium hydroxide.

Solid-state ${ }^{29} \mathrm{Si}$ magic angle spinning nuclear magnetic resonance analysis: The ${ }^{29} \mathrm{Si}$ NMR spectra of the 28 -day-old hydrated pastes are shown in Fig. 3, respectively. Spectral analyses were performed using the PeakFit software package. The proportion of $\mathrm{Q}^{0 \mathrm{C}}, \mathrm{Q}^{0 \mathrm{~S}}, \mathrm{Q}^{1}, \mathrm{Q}^{2}(1 \mathrm{Al})$ and $\mathrm{Q}^{2}(0 \mathrm{Al})$ were obtained by deconvolution of the single pulse spectra, then the MCL, $\mathrm{Al} / \mathrm{Si}$ ratios and $\alpha_{\mathrm{c}}$ and $\alpha_{\mathrm{s}}$ are calculated according to Refs. ${ }^{7,8}$ and shown in Table-2.

\section{TABLE-2}

PARAMETERS OF MICROSTRUCTURE AND HYDRATION RATE FOR SLAG-CEMENT PASTES

\begin{tabular}{cccccc} 
Samples & $\mathrm{Q}^{2} / \mathrm{Q}^{1}$ & $\mathrm{Al} / \mathrm{Si}$ & $\mathrm{MCL}$ & $\alpha_{\mathrm{c}}(\%)$ & $\alpha_{\mathrm{s}}(\%)$ \\
$50 \%$ slag- $20{ }^{\circ} \mathrm{C}$ & 1.58 & 0.134 & 6.85 & 71.64 & 52.92 \\
$50 \%$ slag-50 ${ }^{\circ} \mathrm{C}$ & 3.94 & 0.142 & 11.29 & 80.85 & 71.43 \\
$50 \%$ slag- $800^{\circ} \mathrm{C}$ & 5.36 & 0.174 & 14.94 & 84.72 & 73.56 \\
$30 \%$ slag- $20^{\circ} \mathrm{C}$ & 1.22 & 0.116 & 4.95 & 65.96 & 54.46 \\
$70 \%$ slag-20 ${ }^{\circ} \mathrm{C}$ & 2.28 & 0.159 & 7.60 & 83.37 & 46.04 \\
\hline
\end{tabular}

As seen in Fig. 3, spectra from slag-cement pastes with $50 \%$ slag curing at different temperatures show three peaks at -79 ppm $\left(\mathrm{Q}^{1}\right),-82 \mathrm{ppm}\left(\mathrm{Q}^{2}(1 \mathrm{Al})\right)$ and -85 ppm $\left(\mathrm{Q}^{2}(0 \mathrm{Al})\right)$ associated with ${ }^{29} \mathrm{Si}$ in hydration products (mainly $\mathrm{C}-\mathrm{S}-\mathrm{H}$ phase) in addition to a peak at around $-71.4 \mathrm{ppm}\left(\mathrm{Q}^{0 \mathrm{C}}\right)$ corresponding to ${ }^{29} \mathrm{Si}$ in pure cement. Also, a weak signal around $-74 \mathrm{ppm}$ $\left(\mathrm{Q}^{\mathrm{oS}}\right)$ can be observed in the spectra corresponding to ${ }^{29} \mathrm{Si}$ in pure slag.

It can be found that $\mathrm{Q}^{0 \mathrm{C}}, \mathrm{Q}^{\mathrm{OS}}, \mathrm{Q}^{1}$ decreased and $\mathrm{Q}^{2}(0 \mathrm{Al})$ increased in intensity with increasing curing temperatures by comparing Fig. 3. Table-2 shows that the $\mathrm{Q}^{2} / \mathrm{Q}^{1}$ and $\mathrm{Al} / \mathrm{Si}$ ratios, MCL, $\alpha_{c}$ and $\alpha_{s}$ increased with increasing curing temperatures, which suggests that a higher degree of polymerization of C-S-H due to more $\mathrm{Si}^{4+}$ are replaced $\mathrm{Al}^{3+}$ into occupied bridging sites in the aluminosilicate chains.

Fig. 3 reveals a striking increase in the intensity of the $\mathrm{Q}^{2}(1 \mathrm{Al})$ and $\mathrm{Q}^{2}(0 \mathrm{Al})$ peak as the slag loading increases, which translates as a clearly increase in MCL (Table-2). The $\alpha_{c}$ increased from 65.96 to $83.37 \%$ and the $\alpha_{\mathrm{s}}$ decreased from 54.46 to 


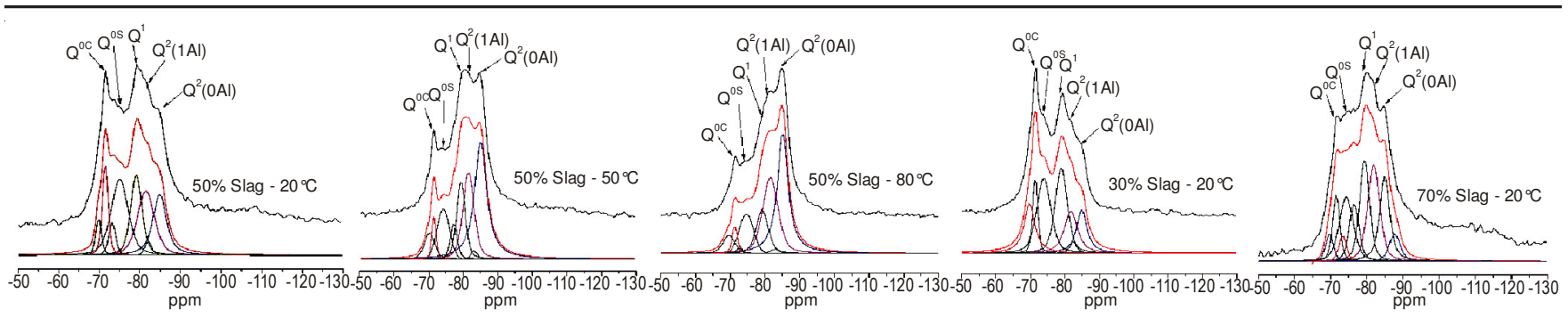

Fig. $3 .{ }^{29} \mathrm{Si}$ NMR spectra of slag-cement pastes
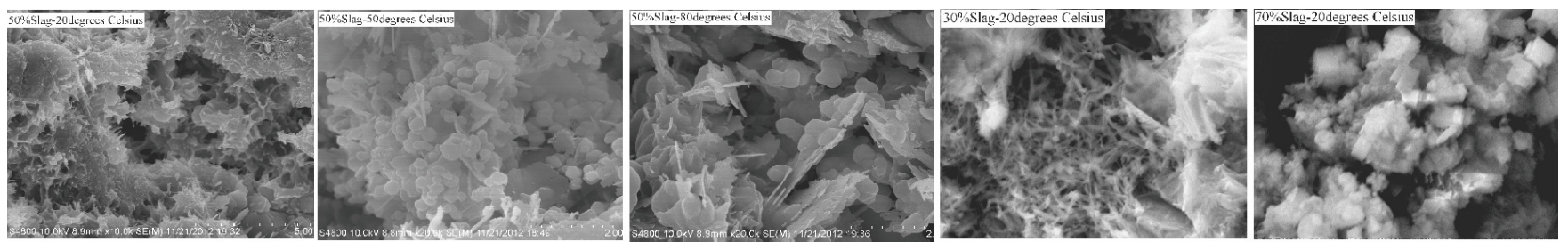

Fig. 4. Micrograph of slag-cement pastes

$46.04 \%$ as increasing slag content from 30 to $70 \%$. These results suggest that the degree of polymerization of $\mathrm{C}-\mathrm{S}-\mathrm{H}$ increased with growing slag content.

Scanning electron microscope analysis: Fig. 4 shows that the morphology of C-S-H tended to be more bulky and dense with the temperature increases. A foil with fibrillar morphology of $\mathrm{C}-\mathrm{S}-\mathrm{H}$ is observed at $20^{\circ} \mathrm{C}$, a dense roundel morphology of C-S-H appear at $50{ }^{\circ} \mathrm{C}$ and a large foil-like morphology is present at $80^{\circ} \mathrm{C}$. There is a progressive change in morphology of C-S-H as the amount of slag in the blends increases, essentially changing from needle and flocculate to graininess in Fig. 4. Where the morphology of $\mathrm{C}-\mathrm{S}-\mathrm{H}$ with $30 \%$ slag is flocculent flocculate, the morphology of C-S-H with $50 \%$ slag is cloudy flocculate and the morphology of C-S-H with $70 \%$ slag is granular flocculate.

\section{Conclusion}

The hydration process of slag-cement pastes are changed as the curing temperatures and slag dosage increases. The hydration heat power increase largely and exothermic peak shift forwards with increasing reaction temperature from 20 $50{ }^{\circ} \mathrm{C}$. But on the contrary, the hydration heat power decrease and exothermic peak shift afterwards with increasing slag content.

The type of hydration product phases of slag-cement pastes is almost changed less as the curing temperatures and slag dosage increases, which includes mainly calcium hydroxide, $\mathrm{C}-\mathrm{S}-\mathrm{H}, \mathrm{C}_{3} \mathrm{~S}$ and $\mathrm{C}_{2} \mathrm{~S}$. However, there is a progressive change in morphology of the C-S-H as the curing temperatures and slag loading increases.

The microstructure parameters of C-S-H are changed substantially as the curing temperatures and slag dosage increases.
It is interesting to note that the intensity of $\mathrm{Q}^{1}$ decrease, $\mathrm{Q}^{2}(1 \mathrm{Al})$ and $\mathrm{Q}^{2}(\mathrm{Al})$ increase and the values of $\mathrm{Q}^{2} / \mathrm{Q}^{1}, \mathrm{Al} / \mathrm{Si}, \mathrm{MCL}, \alpha_{\mathrm{c}}$ and $\alpha_{\mathrm{s}}$ increase due to promoted transformation from $\mathrm{Q}^{1}$ to $\mathrm{Q}^{2}$ as increasing the curing temperatures, which suggests that the degree of polymerization of C-S-H (is enhanced) become higher. In addition, the intensity of $\mathrm{Q}^{1}$ decrease and the values of $\mathrm{Q}^{2} / \mathrm{Q}^{1}, \mathrm{Al} / \mathrm{Si}, \mathrm{MCL}, \alpha_{\mathrm{c}}$ increase with increasing slag content, which suggests that the degree of polymerization of $\mathrm{C}-\mathrm{S}-\mathrm{H}$ is enhanced for more $\mathrm{Al}^{3+}$ replace $\mathrm{Si}^{4+}$ into occupied bridging sites in the aluminosilicate chains.

\section{ACKNOWLEDGEMENTS}

The authors thank the National Basic Research Program of China for funding under Grant No. 2009CB623201, Huaxin Cement Co., Ltd. and Jiangnan grinding Co., Ltd. for supplying materials.

\section{REFERENCES}

1. F.H. Jang, A Study on the Composition, Structure and Performance of Slag-fines Cementing Materials Alkali-activated, Xi'an University of Architecture and Technology, Xi'an (2008) (in Chinese).

2. R. Yang and J.H. Sharp, J. Am. Ceram. Soc., 84, 1113 (2001).

3. C. Famy, K.L. Scrivener, A. Atkinson and A.R. Brough, Cement Concr. Res., 32, 269 (2002).

4. R. Taylor, I.G. Richardson and R.M.D. Brydson, Cement Concr. Res., 40, 971 (2010).

5. A.V. Girão, I.G. Richardson, R. Taylor and R.M.D. Brydson, Cement Concr. Res., 40, 1350 (2010).

6. L. Wang, Z. He, B. ZHANG and X.H. Cai, J. Chinese Ceram. Soc., 38, 2212 (2010).

7. I.G. Richardson, Cement Concr. Res., 29, 1131 (1999).

8. D.S. Shen, R.Y. Lin and C.L. Hwang, J. Chin. Inst. Civ. Hydra Eng., 5, 387 (1993). 